\title{
WALESKA PAIXÃO: UMA BIOGRAFIA A SERVIÇO DA ENFERMAGEM BRASILEIRA
}

\author{
Waleska Paixão: a biography dedicated to the brazilian nursing \\ Waleska Paixão: una biografía al servicio \\ Desarrollo de la enfermería brasileña.
}

\section{RESUMO}

Trata-se de estudo sobre dados históricos de vida de Waleska Paixão, elaborado com o objetivo de analisar suas contribuições mais significativas à Enfermagem brasileira e lançar um primeiro olhar sobre as plenitudes de questões envolvendo experiências vividas por esta enfermeira, em seu tempo. As fontes primárias são documentos do Centro de Documentação da Escola Anna Nery da Universidade Federal do Rio de Janeiro e depoimento oral de Waleska Paixão arquivado na instituição. Os resultados demonstram que a trajetória de vida da protagonista focalizada pelo estudo teve caminho marcante na Enfermagem, particularmente no que concerne a avanços da profissão e do ethos primaz do perfil das(os) enfermeiras(os), líderes na construção pedagógica do ensino de Enfermagem e na edificação da Enfermagem brasileira.

Palavras-chave: História da Enfermagem. Biografia. Legislação de Enfermagem.

\begin{abstract}
This is a study on the life of Waleska Paixão done in order to view her utmost significant contribution to nursing in Brazil and to launch a first look over the complexity of the historical issues of her life during her lifetime. The primary sources came from documents of the Centro de Documentação of Escola Anna Nery at the Universidade Federal do Rio de Janeiro and Waleska Paixão's verbal report archived at the institution. The results, as seen by the study, show that the life path of the protagonist was outstanding, concerning primarily the progress of the profession and the utmost ethos of the nurses' profile, educational leaders in the construction of teaching, nursing and the building of nursing brazilian.
\end{abstract}

Key words: Nursing History. Biography. Legislation, Nursing

\section{Resumen}

Se trata de un estudio sobre la historia de vida de Waleska Paixão, elaborado con el objetivo de examinar sus contribuciones más significativas para la enfermería brasileña y lanzar una primera visión sobre la complejidad de los problemas históricos vividos en su tiempo por esta enfermera. Las fuentes primarias son documentos del Centro de Documentación de la Escuela Anna Nery de la Universidad Federal de Río de Janeiro y testimonio oral de Waleska Paixão archivado en la institución. Los resultados indican que el camino de vida de la protagonista centralizada por el estudio, tuvo trayectoria expresiva en la enfermería, particularmente en lo que concierne al avance de la profesión y del ethos, como primacía del perfil de las (los) enfermeras(os), líderes de la educación en la construcción de la enseñanza, la enfermería y la construcción de la enfermería brasileña.
Palabras claves: Historia de la Enfermería. Biografía. Legislación de Enfermería.

${ }^{1}$ Enfermeira. Mestranda em Enfermagem da Escola de Enfermagem Anna Nery da Universidade Federal do Rio de Janeiro - EEAN/UFRJ. Membro do Núcleo de Pesquisa de História de Enfermagem Brasileira - Nuphebras. Brasil. E-mail: jarisaazevedo@yahoo.com.br, ${ }^{2}$ Professora Emérita da UFRJ. Líder do Grupo de Pesquisa e Estudos Epistemológicos para a Enfermagem e pesquisadora CNPq. Brasil. E-mail: vilma@eean.ufrj.br, ${ }^{3}$ Doutora em Enfermagem. Professora Adjunta do Departamento de Enfermagem Fundamental da EEAN/UFRJ. Pesquisadora do Nuphebras. Brasil. E-mail: marialuz@alternex.com.br 


\section{CONSIDERACÕES INICIAIS}

Esta pesquisa tem como objeto de estudo fragmentos da história de vida de Waleska Paixão, enfermeira diplomada pela Escola de Enfermagem Carlos Chagas, da Universidade Federal de Minas Gerais - EECC/UFMG, que muito contribuiu para o avanço do ensino de Enfermagem no Brasil. A intenção é lançar um primeiro olhar sobre a complexidade das questões históricas vividas por Waleska Paixão e suas contribuições ao desenvolvimento da profissão. Especificamente, os objetivos são: apresentar breves notas biográficas de Waleska Paixão e analisar as suas contribuições mais significativas à Enfermagem brasileira.

Trata-se de pesquisa de cunho histórico-social, cujo caminho metodológico orienta-se para a descrição dos fatos e fenômenos pertinentes à biografia desta personagem da História da Enfermagem Brasileira. As fontes primárias foram documentos do Centro de Documentação da Escola Anna Nery da Universidade Federal do Rio de Janeiro - CEDOC/EEAN/UFRJ: curriculum vitae de Waleska Paixão; correspondências; jornal; revista; documentos oficiais da UFRJ, entre outros. Além disso, consultou-se o depoimento oral de Waleska, concedido às professoras leda de Alencar Barreira e Raimunda da Silva Becker, em 1993, arquivado também no referido acervo. As fontes secundárias foram constituídas por livros, periódicos sobre: história da Enfermagem, história do Brasil e legislação de enfermagem. Do ponto de vista analítico, utilizaram-se procedimento de leitura e apreciação crítica, que permitiram a ordenação cronológica e temática, de forma a atender aos objetivos do estudo.

\section{WALESKA PAIXÃO: dados pessoais e profissionais}

A personagem em foco nasceu no dia 3 de novembro de 1903, em Petrópolis, Rio de Janeiro, onde cursou o ensino fundamental e médio. Excepcionalmente, de fato, ela aprendeu a escrever corretamente em sua própria língua - português e, também, a comunicar-se em três línguas estrangeiras: inglês, francês e espanhol. Waleska era a sexta filha de seus pais, Ludovinia Vale Paixão e Henrique Paixão, e tinha dois irmãos e cinco irmãs. 0 pai era engenheiro, e a mãe detinha capital cultural apreciável para os padrões da época. E com a experiência de casa, ela mesma tornou-se professora e catequista autodidata, lecionou desde os 14 anos de idade no Externato Paixão, fundado por seu avô, e assumiu a diretoria do mesmo, por algum tempo'.

Assim, na segunda década do século XX, enquanto o mundo vivenciava as consequências da primeira Guerra Mundial e, para piorar a situação, ocorria a pandemia da Gripe Espanhola, nossa protagonista, com apenas 15 anos, aprendeu quase que, por intuição, o "oficio de enfermeira". A exemplo: participou do cuidado de sua irmã mais velha quando esta contraiu a gripe espanhola e necessitava de constantes visitas médicas, muitas das vezes apenas para assegurar a administração de medicamentos injetáveis, com o intuito de amenizar a sintomatologia da gripe. Um dia, sua irmã precisava com urgência de uma dessas aplicações; entretanto, o médico encontrava-se distante da residência. Ela relembra:

Eu achei um absurdo esperar [o médico para aplicar] uma injeção para um caso assim, gravíssimo, $e$ perguntei ao médico se havia alguma dificuldade, se eu não podia aprender a dar a injeção?

A partir deste desafio, ela aprendeu a praticar procedimentos técnicos de enfermagem mais simples, apoiandose nas orientações do médico. Durante a ocorrência da gripe espanhola, ela, mais tarde brilhante enfermeira, não só administrou medicamentos em sua irmã, mas também prestou esse tipo de cuidado à vizinhança acometida pela moléstia, a pedido do próprio médico ${ }^{2}$. Todavia, o envolvimento formal com a Enfermagem só ocorreu aos 33 anos de idade, embora ela tivesse cogitado fazer o curso de Enfermagem aos 19 anos, a despeito da resistência de sua mãe, como se depreende na entrevista:

(...) quando eu tinha dezenove anos, eu vi, numa vitrine, um anúncio da Escola Anna Nery, que estava começando. E eu tive vontade de ir. Mas eu tinha certeza de que minha mãe não deixava. Naquele tempo, praticamente a enfermagem não existia ${ }^{2}$.

Em 1933, Waleska foi convidada por Laís Netto dos Reys, amiga se sua família e que, à época, dirigia a Escola de Enfermagem Carlos Chagas - EECC em Belo Horizonte, para lecionar a disciplina Drogas e Soluções, pois havia uma carência de professoras na Escola. Ademais, o conteúdo desta disciplina estava mais relacionado a cálculos do que conhecimento específico em enfermagem. Em seu depoimento, ela esclarece que relutou em aceitar a incumbência; apesar de deter conhecimento em cálculos, alegou não ter preparação especializada para a atribuição. Porém, diante da insistência e persuasão de Dona Laís, sentiu-se convencida a aceitar a incumbência, esclarecerendo:

Então, eu comecei na Escola como professora, depois passei a aluna².

Como se pode inferir, concomitantemente, Waleska foi professora e aluna. Durante o período em que estudou e lecionou na EECC, também prestou serviços na área administrativa, sob a supervisão de Laís Netto dos Reys, pois já dispunha de conhecimentos administrativos, adquiridos no Externato Paixão?.

Aos 35 anos, Waleska recebeu o diploma de enfermeira e, após quatro meses de formada, foi designada para assumir o cargo de Diretora da EECC, onde trabalhou arduamente e conseguiu a equiparação da EECC ao padrão Anna Nery, em $1942^{3}$. 
Em 1943, vislumbrou e aproveitou a oportunidade de cursar pós-graduação em Administração e Ensino de Enfermagem na Universidade de Cornell, Nova York, com bolsa de estudo custeada pelo Instituto de Assuntos Interamericanos. Após 10 meses no exterior, regressou ao Brasil, para dar continuidade ao seu trabalho na EECC?

Em 1946, mobilizou-se para a criação de um órgão defensor do exercício da profissão de enfermagem, em Minas Gerais. Na ocasião, a única entidade de classe da Enfermagem era a Associação Brasileira de Enfermeiras Diplomadas - ABED, criada em 1926, no Rio de Janeiro, hoje Associação Brasileira de Enfermagem - ABEn; naquele momento iniciava-se um movimento de expansão, sendo que já tinham sido criadas três seções estaduais da entidade, em território brasileiro, respectivamente São Paulo, Rio de Janeiro e Amazonas. Consciente de seu intuito, reuniu algumas enfermeiras que comungavam de seu ideal e articulou a criação de uma Seção Estadual da ABED em Minas Gerais².

É pertinente recordar que, desde sua criação em 1926, a ABED não contemplava em seu estatuto qualquer capítulo ou artigo referente à fundação de seções estaduais. Todavia, a partir da década de 1940 ganhou força e foi bem aceita a idéia de fundar seções estaduais. Em 26 de abril de 1945, foi fundada em São Paulo a primeira seção estadual, cujo reconhecimento ocorreu em 1948. Com o pioneirismo da seção de São Paulo foram criadas, respectivamente, as seções dos estados do Rio de Janeiro e Amazonas em 1946. No estatuto da ABED de 1946, foi incluído um capítulo sobre os pré-requisitos para a criação de seções estaduais, que, em um de seus artigos, exigia no mínimo cinco enfermeiras para fundar uma seção 4 .

De acordo com depoimento de nossa personagem, em 05 de fevereiro de 1947, com muito esforço dessas enfermeiras de "garra", foi criada a ABED - Seção MG, tornando-se Waleska Paixão sócia fundadora e primeira presidente dessa seção². Todavia, o reconhecimento da mesma seção só ocorreu dois anos depois de sua criação, como ela destaca:

(...) Eu chamei as colegas e propus que nós começássemos (...), nós fundamos a seção ABED de Belo Horizonte e pedimos então que ela fosse reconhecida?.

\section{DIRETORA DA ESCOLA DE ENFERMAGEM ANNA NERY}

Com a saúde debilitada e emocionalmente preocupada com a família, em 1948, nossa protagonista pediu a exoneração do cargo de Diretora da Escola e retornou ao seu estado de origem, Rio de Janeiro, para permanecer próxima de sua família, residente em Petrópolis. Em paralelo, aproveitou para aceitar o convite de Laís Netto dos Reys, que à época dirigia a Escola de Enfermagem Anna Nery, para trabalhar na referida escola. Segundo suas palavras:
(...) Eu tinha tido hepatite no princípio do ano. Eu tinha ficado bastante abatida, (...) recebi notícia de casa que meu pai estava doente, estava cardíaco e vinha piorando muito?.

Em junho do mesmo ano, foi admitida na EAN segundo a Portaria n n$^{0} 91$ de 24 de junho de 1948; publicada no Diário Oficial de 30/06/1948, sendo sua posse para exercer o cargo de enfermeira, em 01 de julho de 1948.

\section{(...) Então eu fui pra Ana Néri em 1948 e comecei a trabalhar.}

Após dois anos no cargo de professora e de atividades de contribuição à diretoria da Escola, em 10 de julho de 1950, foi nomeada pelo Presidente da República, Eurico Gaspar Dutra, para exercer o cargo de Diretora da Escola Anna Nery da Universidade do Brasil, vago em virtude do falecimento de D. Laís.

Ela foi Diretora da EEAN durante 16 anos (1950-1966) utilizando principalmente a sua inteligência e determinação para alcançar êxito nas lutas travadas em prol do crescimento e desenvolvimento da profissão, em especial garantindo os avanços da EAN. Cabe destacar durante a sua gestão a promoção de Reuniões de Diretoras de Escolas de Enfermagem brasileiras realizadas na EAN, onde foram discutidas questões relativas ao ensino de enfermagem. Acrescente-se especial atenção à formação docente, através da obtenção de bolsas de estudos para encaminhar aos Estados Unidos várias professoras da própria escola. Ainda na qualidade de diretora da EAN, desempenhou várias atividades, tais como: professora das disciplinas de Ética Profissional, de História e Legislação de Enfermagem. ${ }^{a}$

\section{ALGUMAS CONTRIBUICÕES PARA O ENSINO E A PRÁTICA DE ENFERMAGEM NO ÂMBITO DA ABED}

No mesmo ano em que assumiu a direção da Escola, foi eleita presidente da ABED no período 1950-1952 e membro do Conselho Deliberativo desta entidade de 1952 a 1954 e da Subcomissão de Diretoras de 1951 a 1955. Durante sua gestão na EAN, em algumas ocasiões, foi designada pela ABED e pelo Ministério da Educação e Cultura para fazer parte de várias comissões, com propósitos de acompanhar, avaliar, sugerir e apoiar projetos de leis ou emendas que tramitaram nas Casas do Congresso à época. Entre outras, pode-se destacar a Comissão de Legislação da ABED, a qual, Waleska Paixão juntamente com outras ilustres enfermeiras, reivindicou a retificação de cargo e reclassificação da enfermagem entre os serviços profissionais de nível médio.

Esta luta refere-se à publicação, em 1954, dos estudos da Comissão do Plano de Classificação de Cargos do Departamento Administrativo do Serviço Público - DASP. Este estudo transformou-se em projeto de lei que tramitou nas Casas do 
Congresso, durante seis anos, acompanhado de forma persistente pela Comissão de Legislação da $\mathrm{ABEn}{ }^{4}$.

Entretanto, somente em 12 de julho de 1960, foi sancionada a Lei $\mathrm{n}^{0} 3.780$, pelo presidente Juscelino Kubitschek, dispondo sobre a Classificação de Cargos do Serviço Civil do poder executivo, sendo considerado de grande importância o status da Enfermagem. Pode-se considerar que essa Lei posicionou o enfermeiro como profissional técnico-científico de nível superior no serviço público federal, bem como contribuiu para o reconhecimento do enfermeiro como categoria de nível universitário, com remuneração condizente ${ }^{5}$. Destacamos, ainda, o trabalho da Comissão de Legislação da ABED para tornar realidade a Lei ${ }^{\circ}$ 2.604/55 - Lei do Exercício Profissional, sancionada pelo presidente da república João Café Filho.

Esta lei foi importante para evolução da Enfermagem, visto que o exercício da profissão passou a ter, de modo mais especificado, uma legislação própria, independente de outros profissionais. Cumpre dizer que as atividades da Comissão de Legislação foram iniciadas com um Plano de Trabalho elaborado pela Waleska, quando presidente da entidade em 1951.

Também merece relevo, nessa ocasião, a indicação de uma Comissão para o estudo do Código de Ética da Enfermagem. Em 1951, Waleska integrou-se à aludida Comissão. Cabe lembrar que nesse período não havia qualquer instrumento que norteasse os aspectos éticos do exercício da enfermagem. Então, foi necessária a formação dessa comissão para elaborar o referido Código.

Entre vários assuntos conferidos à competência dos membros da mencionada comissão, coube a Waleska a de fazer a introdução. Após várias apreciações e revisões, o anteprojeto foi aprovado, em 13 de outubro de 1958, durante XI Congresso Brasileiro de Enfermagem em Recife 4 .

No que tange às produções, Waleska publicou diversos artigos, em periódicos nacional e internacional. Entre outras, merece relevo: "Formation Pychologique et Morale de l'infirmière" 6 . Contudo, o mais valioso trabalho, fruto da criatividade de nossa personagem é, indiscutivelmente, 0 primeiro livro didático de História da Enfermagem, publicado em 1951, "Páginas de História de Enfermagem", o qual foi relevante não só para apoiar a transmissão pedagógica, mas para o entendimento e esclarecimento da história da Enfermagem como profissão, elucidando aspectos relevantes alusivos ao surgimento da Enfermagem em diversos países. Após várias reedições, o livro continua bastante utilizado até os dias de hoje por docentes e discentes de Enfermagem? ${ }^{7}$.

\section{O RECONHECIMENTO PROFISSIONAL}

As distinções de Waleska Paixão tiveram início em 1959, quando o diretor da Casa de Saúde e Maternidade Arnaldo de Moraes criou o "Prêmio Waleska Paixão" a ser concedido à diplomada que obtivesse destaque técnico e ético profissional. ${ }^{\mathrm{a}}$

Em 1960, Waleska Paixão foi indicada pela Assembléia Legislativa do RJ para a concessão do título de "cidadã carioca", distinção que foi justificada até por sua bagagem intelectual, como percebemos neste recorte documental:

\section{(...) tendo realizado diversos cursos no Brasil e no estrangeiro e autora de numerosos trabalhos literários e de especialização em Enfermagem e por suas concretas contribuições. ${ }^{a}$}

Em 1968, durante o XX Congresso Brasileiro de Enfermagem, Waleska Paixão recebeu o primeiro prêmio "Enfermeira do Ano", representado por uma medalha de prata, oferecido pela Johnson \& Johnson ${ }^{\circledR}$. A cerimônia contou com a presença de pessoas ilustres, como o governador de Pernambuco, Sr. Salviano Machado, do prefeito, Sr. Augusto Lucena, dos secretários de saúde de Pernambuco e da Paraíba, de líderes da ABEn e do representante da Johnson \& Johnson ${ }^{\circledR}$, João Alfredo Mendes, que, representando o seu presidente, fez a entrega do prêmio a Waleska ${ }^{8}$.

Adicionalmente, cabe destacar que a própria EEAN reconheceu o valor de sua contribuição, quando em 1983, encaminhou processo à Universidade Federal do Rio de Janeiro, para que Ihe fosse outorgada a mais elevada honraria acadêmica: o Título de Doutor Honoris Causa, somente "concedido a personalidades nacionais e estrangeiras de alta expressão" 9:19.

Isto aconteceu, realmente, às 10 horas do dia 3 de maio de 1983, em cerimônia realizada na sala das Congregações do Centro de Ciências da Saúde da UFRJ, onde Waleska Paixão recebeu do Vice-Reitor professor Dr. Jorge de Abreu Coutinho a outorga do título honorífico?

Após sua gestão como Diretora da EEAN, já aposentada, Dona Waleska aceitou o convite da Arquidiocese de Sergipe para realizar um trabalho social na cidade de Santa Rosa de Lima. Em trecho da entrevista, ela expressa os seus motivos:

(...) eu sempre tive pena desses lugares abandonados e tinha uma vontade de dar uma mãozinha num lugar abandonado².

Os resultados desta dedicação a uma região tão pobre do país, segundo suas palavras, foram:

Construções de maternidade com seis leitos, uma creche com quarenta e cinco crianças, uma escola maternal com jardim de infância com cento e quarenta e cinco crianças e uma escola primária com duzentos e cinquenta crianças².

Essas conquistas devem-se à habilidade e conhecimento de Waleska Paixão para reivindicar às autoridades locais o financiamento das obras sociais. Assim, com base nessas informaç̃̃es, cumpre afirmar que nossa personagem lutou com muita dedicação e amor à profissão de enfermeira por transformaç̧̃̃es sociais. 


\section{CONSIDERAÇÕES FINAIS}

Os resultados alcançados nas investigações demonstraram que Waleska Paixão proporcionou contribuição significativa para os avanços da Enfermagem e, em especial, para a evolução do ensino da profissão. Sua dedicação, sabedoria, simplicidade, pertinácia e perseverança marcante mostram que seus esforços foram bem sucedidos a serviço da causa da Enfermagem, e, em particular, merece elevada consideração seu espírito humanitário em relação às atividades pedagógicas e de assistência social à comunidade de Santa Rosa de Lima-ES. Por suas peculiaridades pessoais e profissionais, nossa protagonista está inserida no banco de dados denominado Quem é Quem na História da Enfermagem Brasileira, do Núcleo de Pesquisa de História de Enfermagem Brasileira - Nuphebras.

Por último, em 1993, com quase 90 anos de idade, Dona Waleska retornou a Petrópolis, devido a problemas de saúde, vindo a falecer em 25 de novembro do mesmo ano - Dia de Ação de Graça -, quando a Enfermagem perdeu, de fato, uma ilustre guerreira e defensora das causas da profissão ${ }^{a}$.

\section{REFERÊNCIAS}

1. Paixão W. Hoje, mais do que ontem. Rio de Janeiro (RJ): PAT Serviços e Produções Gráficas; 1987.

2. Paixão W. Entrevista concedida às professoras leda de Alencar Castro Barreira e Raimunda da Silva Becker. Rio de Janeiro (RJ): Centro de Documentação/ EEAN/UFRJ; 1993.

3. Nascimento ES, Santos GF, Caldeira VP. Criação, quotidiano e trajetória da Escola de Enfermagem da UFMG: um mergulho no passado. Belo Horizonte (MG): EECC/ UFMG; 1999.

4. Carvalho AC. Associação Brasileira de Enfermagem (1926-1976): documentário. Brasília (DF): ABEn; 1976.

5. Oguisso T, Moreira A, Freitas GF, organizadores. Trajetória histórica e legal da enfermagem. Barueri (SP): Manole; 2005.

6. Paixão W. A formação moral da estudante de enfermagem. Rev Bras Enferm 1952 jan; (5): 17- 23.

7. Paixão W. História da enfermagem. $4^{\mathrm{a}}$ ed. Rio de Janeiro (RJ): Buccini; 1969.

8. Waleska Paixão: recebe a primeiro prêmio "Enfermeira do ano". Rev Johnson \& Johnson ${ }^{R} 1968$ ago; (2): 22.

9. Ministério da Educação e Cultura (BR). Regimento do Conselho Universitário. Rio de Janeiro (RJ): UFRJ; 1970. p. 19.

\section{NOTA}

${ }^{a}$ Trabalho proveniente do Relatório de Bolsista de Iniciação Cientíica, parte integrante do projeto "Saltos Evolutivos da Enfermagem Documentos históricos da EEAN/UFRJ 1951/1974", coordenado pela Profa. Dra. Vilma de Carvalho, o qual trata de classificar os documentos do Acervo Arquivístico da Escola de Enfermagem Anna Nery, organizando fontes primárias de referência para a História de Enfermagem. 0 Relatório se configurou como Trabalho de Conclusão de Curso de Graduação da Escola de Enfermagem Anna Nery da Universidade Federal do Rio de Janeiro, apresentado em julho de 2006. 